\title{
Crosstalk between toll-like receptors and hypoxia-dependent pathways in health and disease
}

\author{
Bianca Crifo, Cormac T Taylor
}

School of Medicine and Medical Science, UCD Conway Institute, University College Dublin, Belfield, Dublin, Ireland

\section{Correspondence to Cormac T Taylor, UCD \\ Conway Institute, University College Dublin Belfield, \\ Dublin 4, Ireland; cormac taylor@ucd.ie}

Received 20 May 2015 Revised 1 July 2015 Accepted 6 July 2015 Published Online First 11 January 2016

Copyright (@) 2016 American Federation for Medical Research

\section{CrossMark}

To cite: Crifo $B$, Taylor CT. J Investig Med 2016;64:369-375.

\begin{abstract}
Toll-like receptors (TLRs) play an important role in shaping the host immune response to infection and inflammation. Tissue hypoxia is a common microenvironmental feature of infected and inflamed tissues. Furthermore, hypoxia significantly impacts the development of immune and inflammatory responses through the regulation of host innate and adaptive immunity. Here, we will discuss current knowledge in relation to the crosstalk that exists between toll-like receptor- and hypoxia-dependent signaling pathways in health and disease.
\end{abstract}

\section{TOLL-LIKE RECEPTORS}

The 'natural immune system' was first described by Elie Metchnikoff in the late 1800s. Subsequent work identified the importance of this system in the mammalian defense response to microbial infection. Our current view of the mammalian immune system identifies 2 main branches, termed innate and adaptive immunity, which in turn includes the cellular and humoral arms. The main function of these systems is to mediate the destruction and removal of invading pathogens as well as to initiate repair mechanisms designed to restore homeostasis to damaged tissues after infection and inflammation. ${ }^{1}$

Toll-like receptors (TLRs) comprise an ancient component of innate immunity whereby host organisms can identify the presence of microbial infection through a family of receptors, which recognize conserved microbespecific structural patterns and elicit a defensive immune response accordingly. ${ }^{2}{ }^{3}$ The toll gene was first described during a study of embryogenesis of Drosophila melanogaster. Flies with a mutated toll gene produce embryos with an underdeveloped ventral portion. ${ }^{4}$ Subsequent studies revealed that the toll gene was not only involved in dorsal-ventral axis development but that loss of function in toll protein also resulted in a greatly increased susceptibility to fungal infection, a discovery that led to the identification of the toll genes having a key role in innate immunity. ${ }^{5}$

Subsequently, a homologue of the toll gene was discovered in humans, which encodes a receptor that controls activity of nuclear factor $\kappa \mathrm{B}(\mathrm{NF}-\kappa \mathrm{B})$, a master transcriptional regulator of host immunity. ${ }^{6}$ in mammals and other vertebrates, toll homologue proteins were termed TLRs and formed part of a wide family of receptors called pattern-recognition receptors, which play a key role in pathogen recognition and innate immunity. To date, 10 members of the TLR family have been identified in humans ${ }^{7}$ with each isoform recognizing distinct microbial motifs.

\section{TOLL-LIKE RECEPTOR LOCALIZATION AND PATHOGEN-ASSOCIATED MOLECULAR PATTERN LIGANDS}

Toll-like receptors are expressed on cells of the innate and adaptive immune system as well as onnonimmune cells including fibroblasts and epithelial cells. $^{2}$ TLR1, TLR2, TLR4, TLR5, TLR6, and TLR10 are plasma membrane proteins, which recognize microbe-specific motifs known as pathogen-associated molecular patterns (PAMPs) in the extracellular environment. ${ }^{2}$ TLR4 is a receptor for lipopolysaccharide (LPS), which is a constituent of the cell wall of gram-negative bacteria. ${ }^{8}$ TLR2 is the receptor for a range of PAMPs including peptidoglycan from grampositive bacteria, ${ }^{9}$ 10 lipoarabinomannan from mycobacteria, ${ }^{11}$ glycosylphosphatidylinositol from Trypanosoma cruzi, ${ }^{12}$ zymosan from yeast, ${ }^{13}$ and hemagglutinin protein from viruses. ${ }^{14}$ The broad range of ligands recognized by TLR2 could be explained by the heterodimerization, which occurs between TLR2 and other TLRs (including TLR1 and TLR6). ${ }^{15}{ }^{16}$ Flagellin, a principal component protein of bacterial flagella, is sensed by TLR5. ${ }^{17}$ TLR10 remains an orphan receptor, but it has been reported that its expression is enhanced in response to reactive oxygen species (ROS) in hypoxic cells ${ }^{18}$ and virus influenza infection. ${ }^{19}$ Moreover, TLR10 has been reported to heterodimerize with TLR-2 in sensing triacylated lipopeptides. ${ }^{20}$

TLR3, TLR7, TLR8, and TLR9 are intracellular receptors, localized in endosomal compartments of macrophages and dendritic cells (DCs) and are involved in the recognition of nucleic acids derived from pathogens during their replication. ${ }^{21}$ TLR7, TLR8, and TLR9 exist as preformed dimers in endosomal compartments. ${ }^{22} 23$ TLR3 is expressed predominantly in $\mathrm{DCs}^{24}$ and is a cell surface receptor for dsRNA from viruses. ${ }^{25}$ TLR7 recognizes ssRNA from viruses, ${ }^{26}$ fungi, ${ }^{27}$ and bacteria ${ }^{28}$ 
and detects siRNA. ${ }^{29}$ In humans, TLR8 is similar to TLR7 and it recognizes viral ssRNA. ${ }^{21}$ TLR9 detects short unmethylated sequences of dsDNA from bacteria, ${ }^{30}$ viruses, ${ }^{31}$ and protozoa. ${ }^{32}$

To avoid exposure to endogenous nucleic acids, the internal TLRs are retained within the endoplasmic reticulum (ER) in unstimulated cells and rapidly translocate to the endosome via the Golgi apparatus before stimulation. Two proteins residing in the ER called PRAT4A (protein associated with TLR 4) 33 and the UNC93B1 (12-transmembrane spanning Unc-93 homologue B1) ${ }^{34} 35$ traffic TLR3, TLR7, and TLR9 from the ER to the endo-some. Within the endosome, TLR7 and TLR9, but not TLR3, are cleaved by proteases including endopeptidase and cathepsins, and this cleavage is crucial for the activation of downstream signaling. PRAT4A also regulates the trafficking of TLR1, TLR2, and TLR4 from the ER to the plasma membrane. ${ }^{33}$

\section{TOLL-LIKE RECEPTOR STRUCTURE AND COMPLEXES}

Toll-like receptors are transmembrane proteins, with an extracellular leucine rich-repeat (LRR) domain. ${ }^{3}$ The LRR domain mediates the recognition of PAMPs or nucleic acids. A cytosolic toll-IL-1 receptor (TIR) domain activates the intracellular signal. ${ }^{37}$

This domain is also present in the type $1 \mathrm{IL}-1$ receptor (IL-1R1); therefore, IL-1R1 and TLRs share some properties and activate similar downstream signaling pathways. ${ }^{38}$ Additional extracellular proteins help some TLRs enhance the binding of the ligand to the receptor. For example, LPS binds a circulating protein termed LBP (LPS-binding protein), which interacts with the plasma membrane protein CD14. ${ }^{39}$ The CD14-LBP-LPS complex binds to the TLR4 that is associated with myeloid differentiation factor 2 on the cell surface, ${ }^{40}$ and together they initiate signal transduction. Activation of TLRs leads to the induction of 2 main pathways. First, the NF-kB pathway is involved in the transcription of many proinflammatory genes such as cytokines and chemokines. Second, the interferon regulatory factor (IRF) pathway orchastrates the antiviral response. The binding of the ligand to its cognate TLR induces a conformational change that activates the receptor, allowing the intracellular TIR domain to dimerize with adaptor proteins that also contain a TIR domain. The following 5 adaptors have been identified thus far: MyD88 (myeloid differentiation primary response protein 88), TRAM (Trif-related adapter molecule), MyD88 adaptor like (MAL, also known as TIRAP), TIR-domain-containing adaptor protein inducing IFN $\beta$ (TRIF), and sterile $\alpha$ - and armadillo-motif-containing protein (SARM). ${ }^{41}$

MyD88 was the first adaptor found to be involved IL-1R1 and TLR signaling. ${ }^{42}$ It transmits the signal that culminates in activation of the MAP (mitogen-activated protein) kinase cascade and NF-kB. The activation of these 2 signaling pathways by most TLRs is unresponsive in cells lacking MyD88. ${ }^{43}$ Exceptions to this are TLR3 and TLR4, which use different adaptor proteins (described later). For TLR7, TLR8, and TLR9 signaling, MyD88 is required for the activation of NF-kB and IRF1, ${ }^{44}$ IRF5,${ }^{45}$ and IRF7. ${ }^{46}$

TLR4 is the only TLR that can use all adaptor proteins. It activates the following 2 distinct pathways: firstly, the MyD88- dependent pathway that leads to the early-phase activation of NF- $\mathrm{KB}$ and, secondly, MAP kinases and the
TRIF-dependent pathway, which mediates the late-phase activation of NF- $\mathrm{KB}$ and MAP kinase signaling. ${ }^{47}$ MyD88 adaptor like is an additional adaptor used as a bridge to recruit MyD88 only for signaling by TLR2 and TLR4. ${ }^{41}$ TLR3 recruits TRIF to mediate the activation of NF- $\mathrm{KB}$, IRF3, IRF5, and IRF7. ${ }^{41}$ TRAM, the fourth adaptor that was discovered, is a bridge protein used by TLR4 to bind TRIF. $^{47}$ SARM represses both TRIF and MyD88 pathways and thus has a distinct role from the others adaptors. ${ }^{48}$

\section{NF-кB SIGNALING}

Nuclear factor $\kappa \mathrm{B}$ proteins are transcription factor dimers, which are ubiquitously expressed in mammalian cells. There are 5 NF- $\mathrm{kB}$ subunits in mammals termed RelA/p65,

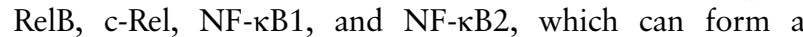
variety of homodimers and heterodimers that are kept inactive in the cytoplasmic compartment in the basal state by association with inhibitory proteins termed IкB. ${ }^{49}$

The recruitment of MyD88 to the activated (ligandbound) TLR leads to its heterodimerization with the DD domain of MyD88 with the DD domain of IRAK4 (IL-1R1-associated protein kinase 4).$^{50}$ MyD88-IRAK4 complexes associate with IRAK1 and IRAK2 in a complex called the 'Myddosome' that subsequently activates a ubiquitin protein ligase (E3) called TRAF6 (tumor necrosis factor receptor-associated factor 6). ${ }^{51}$ TRAF6, together with UBC13 and UEV1, induces the formation of polyubiquitin chains linked on Lys63 (K63) on TRAF6 itself and IRAK1. The polyubiquitin chains lead to the colocalization of NEMO and TAK1 (a MAP3K protein) and subsequently to the activation of MAP kinase cascade and to NF- $\mathrm{KB}$ activation. ${ }^{52}$ NEMO is part of the IKB kinase (IKK) complex formed with IKK $\alpha$ and IKK $\beta$. When TAK1 activates the IKK complex by phosphorylation, IKK phosphorylates IкB, leading its degradation via the ubiquitin/proteasome pathway. Consequently, NF- $\mathrm{KB}$ dimers can translocate to the nucleus and initiate the transcription of hundreds of genes involved in the inflammatory response. ${ }^{53}$ The adaptor proteins and signaling pathways activated by TLR receptors are summarized in figure 1.

\section{HYPOXIA AND THE HYPOXIA-INDUCIBLE FACTOR PATHWAY}

Atmospheric oxygen levels have played a significant role in shaping metazoan evolution for the last billion years. ${ }^{54}$ The first living cells, which appeared on the planet approximately 4 billion years ago, were simple prokaryotes. Because oxygen was not present in the early atmosphere, these cells likely generated their adenosine triphosphate (ATP) through fermentation. During early evolution, organisms evolved to produce energy by harnessing sunlight during photosynthesis, where they were able to synthesize organic molecules using $\mathrm{CO}_{2}$ as a carbon source. ${ }^{55}$ The subsequent evolution of photosynthetic cyanobacteria resulted in the accumulation of $\mathrm{O}_{2}$ in the atmosphere. The rate of accumulation was slow at first because initially it was absorbed into the planet's bedrock during the oxidation of inorganic minerals such as iron. ${ }^{55}$ However, this was eventually saturated and followed by an inexorable accumulation of $\mathrm{O}_{2}$ in the planet's air, which initially caused a mass extinction of much of the earth's early biomass and finally stabilized at around $15 \%$ to $20 \%$ 


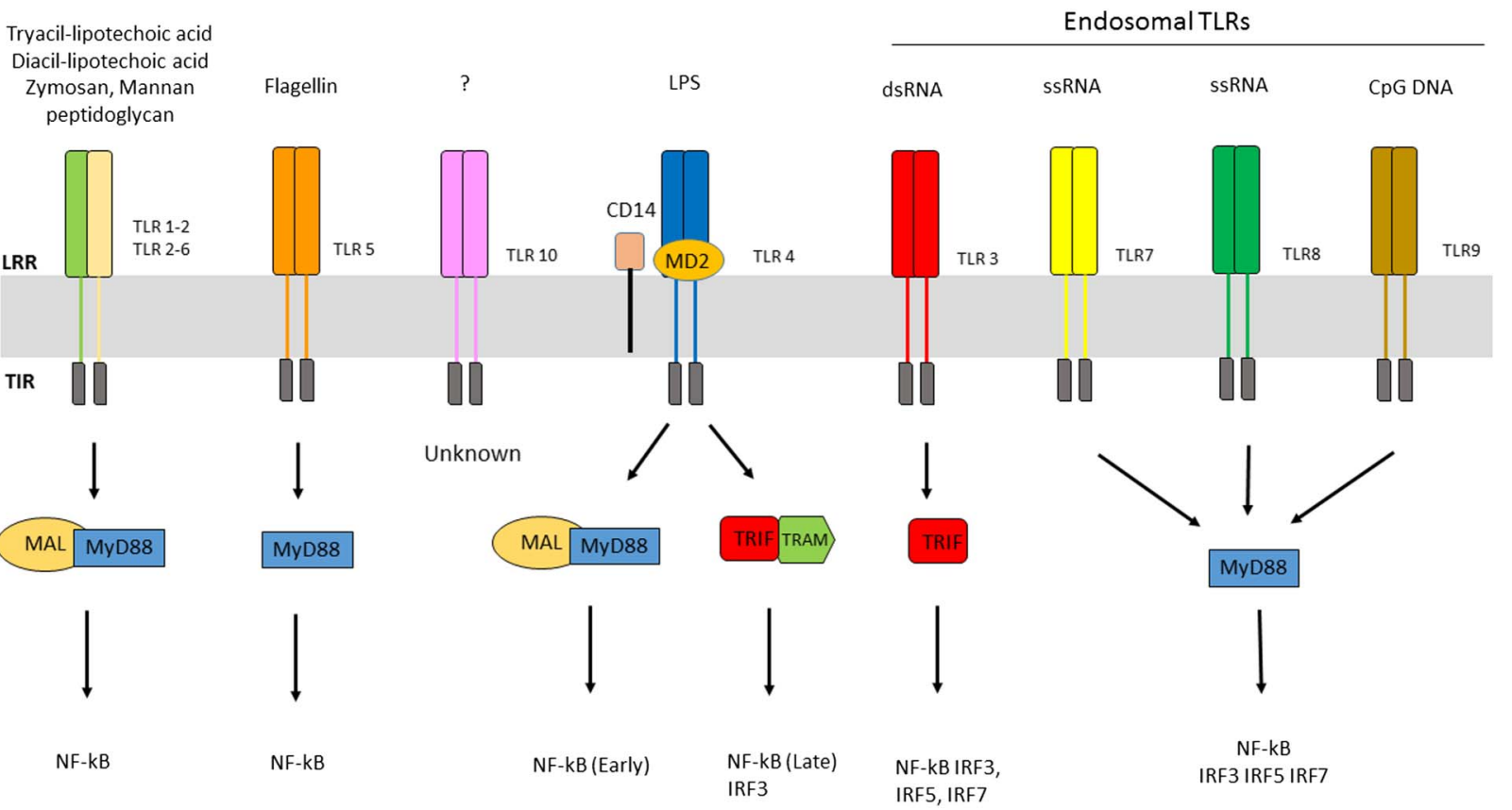

Figure 1 Toll-like receptors in humans. Distinct TLRs discriminate between different microbial patterns. The extracellular LRR domain of each TLR is involved in recognizing its specific microbial ligand, whereas the intracellular TIR domain serves to assemble adaptor protein complexes. All TLRs, with the exception of TLR3, use MyD88 to activate downstream signaling pathways. In some cases (eg, TLR2/6, TLR2/1, and TLR4), the MAL adaptor protein mediates the interaction between TLRs and MyD88. TLR3 and TLR4 use TRIF to transmit the downstream signal. In addition, TLR4 recruits TRAM as bridge. TLR4 is the only receptor that use all 4 adaptors.

between 550 and 600 million years ago. ${ }^{54}$ During this time, a subset of eukaryotic organisms evolved the capacity to be not only resistant to the oxidizing effects of oxygen but also to harness its chemical energy for bioen-ergetic purposes through oxidative phosphorylation, an event that played a significant part in the evolution of metazoans.

Eukaryotes evolved to use oxygen as a substrate for oxidative phosphorylation. Pyruvate derived from sugars and fatty acids derived from fats are catabolized to acetylCoA in mitochondria. The acetylCoA enters the Krebs cycle, which provides NADH and $\mathrm{FADH}_{2}, 2$ electron carriers, which are then fed into the electron transport chain within the inner membrane of mitochondria. $\mathrm{NADH}$ and $\mathrm{FADH} 2$ transfer their high-energy electrons from complex I to complex IV, until they react with molecular oxygen in the terminal complex to produce water. This electron flow across the mitochondrial membrane drives the synthesis of ATP from adenosine diphosphate by an ATPase synthase. ${ }^{56}$

In normoxia, mitochondria consume $85 \%$ to $90 \%$ of the oxygen available to cells for the production of 36 molecules of ATP per molecule of glucose consumed. ${ }^{57}$ Therefore, hypoxia represents a significant threat to the maintenance of metabolic homeostasis. This underscores the importance of having sufficient oxygen availability for the maintenance of cellular ATP production to satisfy bioenergetic demand. Given our dependence on oxygen for metabolic homeostasis, it is not surprising that during the course of evolution, we have developed a molecular system to promote adaptation to hypoxia.

In 1992, a nuclear transcription factor termed the hypoxia-inducible factor 1 (HIF-1), which is involved in the regulation of the expression of erythropoeitin, a key hormone for physiologic adaptation to hypoxia was identified. ${ }^{58}$ Subsequently, HIF-1 was found to be the master regulator of oxygen homeostasis because it mediates the adaptive response to hypoxia. Further studies identified that HIF-1 is not only involved in the regulation of erythro-poiesis but also in other important processes, which facilitate adaptation to hypoxia such as altered iron metabolism, apoptosis, angiogenesis, and glucose metabolism. ${ }^{59}$ It is now clear that HIF-1 accumulates in hypoxia and stimulates the transcription of scores of adaptive genes including glycolytic enzymes and proangiogenic factors such as vascular endothelial growth factor (VEGF).

In hypoxia, most cells switch their metabolic strategy to enhanced glycolysis rather than oxidative phosphorylation for the production of ATP. ${ }^{60}$ Hypoxia-inducible factor 1 contributes to this shift to glycolysis by increasing the expression of glucose transporters and glycolytic enzymes. ${ }^{61}$ In hypoxia, HIF-1 also promotes the expression of lactate dehydrogenase $\mathrm{A},{ }^{62}$ which converts pyruvate to lactate and regenerates $\mathrm{NAD}+$, which permits continued glycolysis and ATP production.

During hypoxia, the rate of cellular respiration is also controlled by HIF-1 in 2 distinct ways. Firstly, HIF-1 induces pyruvate dehydrogenase kinase 1 expression to block the conversion of pyruvate to acetyl coenzyme A, thus shunting the pyruvate toward lactate to generate more $\mathrm{NAD}+$ and ATP. This mechanism reduces the rate of mitochondrial respiration and reduces ROS generation, which is toxic for cells. ${ }^{63}$ Secondly, HIF-1 transcriptionally regulates a subunit switch in cytochrome c oxidase (complex IV) that maximizes the efficiency of the mitochondria during the transfer of electrons in the respiratory chains. ${ }^{64}$ 
Hypoxia-inducible factor 1 is a dimer, which consists of a HIF- $1 \alpha$ subunit, which is inducible by hypoxia and of a HIF-1 $\beta$ subunit, which is constitutively expressed. ${ }^{65}$ There are 2 closely related isoforms (termed HIF- $2 \alpha$ and HIF- $3 \alpha$ ) that share structural and functional characteristics with HIF- $1 \alpha$ and also heterodimerize with HIF-1 $\beta$. All HIF proteins consist of a basic helix-loop-helix (HLH)-PAS homology domain, which is required for hetero-dimerization and DNA binding. ${ }^{66}{ }^{67}$ Unique to HIF- $\alpha$ subunits are 2 oxygen-dependent degradation domains located at the $\mathrm{N}$ - and C-terminals of the protein, which are termed the NODDD and CODDD, respectively. There are also 2 transactivation domains, the $\mathrm{N}$-terminal transactivation domain (NAD) and the C-terminal transactivation domain (CAD) ${ }^{68}$

In normoxia, most available oxygen is used by mitochondria for the generation of ATP through oxidative phosphorylation $^{57}$ and the remainder is used in nonmitochondrial functions such as the suppression of HIF- $\alpha$. The HIF- $\alpha$ subunits are ubiquitously produced but rapidly turned over when 'nonmitochondrial' oxygen is available. In 2001, an evolutionarily conserved system for hydroxylation and degradation of HIF- $\alpha$, which is retained between the nematode Caenorhabditis elegans ${ }^{69}$ and mammals, was identified, underscoring the importance of this system for oxygen sensing across species.

The HIF oxygen-sensing system is centered around a family of enzymes called as HIF hydroxylases. ${ }^{70}$ This family consists of the prolyl-hydroxylase domain dioxygenases (PHDs) and factor inhibiting HIF (FIH). To catalize the reaction that involves the hydroxylation of HIF-1, these enzymes require molecular oxygen and 2-oxoglutarate as cosubstrates and ascorbate and iron as cofactors. In the presence of oxygen, PHDs hydroxylate HIF- $1 \alpha$ on proline residues 402 and 564 (localized in NODDD and CODDD domains, respectively). ${ }^{72}$ This results in the degradation of HIF-1 $\alpha$ subunits through ubiquitylation (by the Von Hippel-Lindau protein) and proteosomal degradation. ${ }^{73}$ Factor inhibiting HIF, on the other hand, hydroxylates an asparaginyl residue 803 localized in CAD domain of HIF- $1 \alpha$, which inhibits the recruitment of coactivator complex $\mathrm{CBP} / \mathrm{p} 300$ and results in the inactivation of HIF- $1 \alpha$ subunit transcriptional activity. ${ }^{74}$

During hypoxia, oxygen demand exceeds supply and the mitochondria consume virtually all oxygen available to a cell to maximize ATP production. ${ }^{75}$ As a result of this, there is no oxygen available for nonmitochondrial processes, leading to the inactivation of HIF hydroxylases. ${ }^{76}$ This promotes the stabilization of HIF-1 $\alpha$, which translocates to the nucleus where it binds to hypoxia response elements present in the regulatory regions of target genes (figure 2). In hypoxia, where the mitochondria are inactivated by inhibitors of respiratory chain such as nitric oxide, a redistribution of oxygen toward all compartments outside mitochondria activate the HIF hydroxylases. The hydroxylases do not register hypoxia and HIF-1 $\alpha$ is inactivated. ${ }^{75}$ Because tissue hypoxia is a key feature of a number of infectious and inflammatory conditions, we will next describe the crosstalk, which exists between TLR- and hypoxia- dependent signaling pathways.

\section{CROSSTALK BETWEEN TLR AND HIF PATHWAYS}

Innate immune cells remain largely quiescent in the physiological (noninfected) state because they circulate in the bloodstream or reside in tissues where the oxygen levels are physiologic. In response to an infection, the increase in vascular diameter and permeability along with the increased expression of cell-adhesion molecules on endothelial cells promotes the extravasation of myeloid cells into the now inflamed site of infection. Low levels of glucose and a scarcity of oxygen characterize the inflammatory microenvironment of an infected tissue due to altered metabolism, increased oxygen consumption by neutrophils, and reduced oxygen supply due to disrupted perfusion. It is within such a hypoxic microenvironment that immune cells kill and prevent the spread of invading microorganisms. Therefore, hypoxia and inflammation are often coincidental events and crosstalk between inflammation- and hypoxia-sensitive pathways likely plays an important role in determining the course of infectious disease progression. It has recently become clear that the stabilization of HIF-1 in immune cells is important for the regulation of survival and immune function during inflammation. ${ }^{77} 78$ In the final part of this review, we will summarize what is known about the involvement of HIF-1 and its regulatory hydroxylases in innate immune reactions, focusing on those inflammatory reactions mediated by TLRs.

In myeloid cells, the HIF pathway promotes immune cell survival and can be up-regulated by microenvironmental hypoxia in the site of infection/inflammation. Although the PHD activity strongly depends on oxygen, during infections, alterations of cellular redox balances and iron or metabolite homeostasis may also interfere with PHD catalytic activity. ${ }^{70}$

Hypoxia-inducible factor $1 \alpha$ levels can also be elevated after stimulation of TLRs in a manner, which is largely oxygen independent. Activation of HIF-1 by TLRs is essential for the adaptation of myeloid cells to inflammatory stimuli. In this context, HIF-1 is important for the promotion of angiogenesis, ${ }^{79}$ proinflammatory cytokine production, ${ }^{80}$ myeloid cell maturation, ${ }^{81}$ ATP production, ${ }^{79}$ and transcriptional regulation of TLR expression. ${ }^{82}$ TLR2 or TLR4 activation results in elevated HIF-1 $\alpha$ levels in myeloid cells. The mechanism involved has been most extensively investigated for TLR4. Human monocytes and differentiated macrophages stimulated with LPS under normoxic conditions enhance the transcription of HIF- $1 \alpha$ mRNA through an $\mathrm{NF}-\kappa \mathrm{B}$-dependent mechanism. The activation of NF- $\kappa \mathrm{B}$ in turn is dependent on TLR-dependent activation of the MAP kinase cascade. In hypoxia, the additional posttranslational stabilization of HIF-1 $\alpha$ (due to hydroxylase inhibition) results in enhanced DNA binding. ${ }^{83}$ Therefore, TLR activation by LPS in combination with hypoxia synergistically increases the activity of HIF-1 and consequently the expression of its target genes involved in innate immunity such as iNOS, ${ }^{84}$ VEGF, ${ }^{85}$ and proinflammatory cytokines. ${ }^{80} 86$

A second level of interaction between hypoxia- and TLR- dependent signaling occurs at the level of the HIF hydroxylases. During normoxia, as well as regulating HIF stability, the PHD1 isoform also modulates the activity of the IKK complex, which is core to the regulation of $\mathrm{NF}-\mathrm{KB}$, resulting in altered sensitivity of $\mathrm{NF}-\mathrm{\kappa B}$ pathway in hypoxia. ${ }^{87}$ These findings were recapitulated in a model of LPS-infected macrophages lacking IKK $\beta$ where it was shown that IKK $\beta$ was essential for HIF- $1 \alpha$ accumulation in hypoxic condition. ${ }^{88}$ 

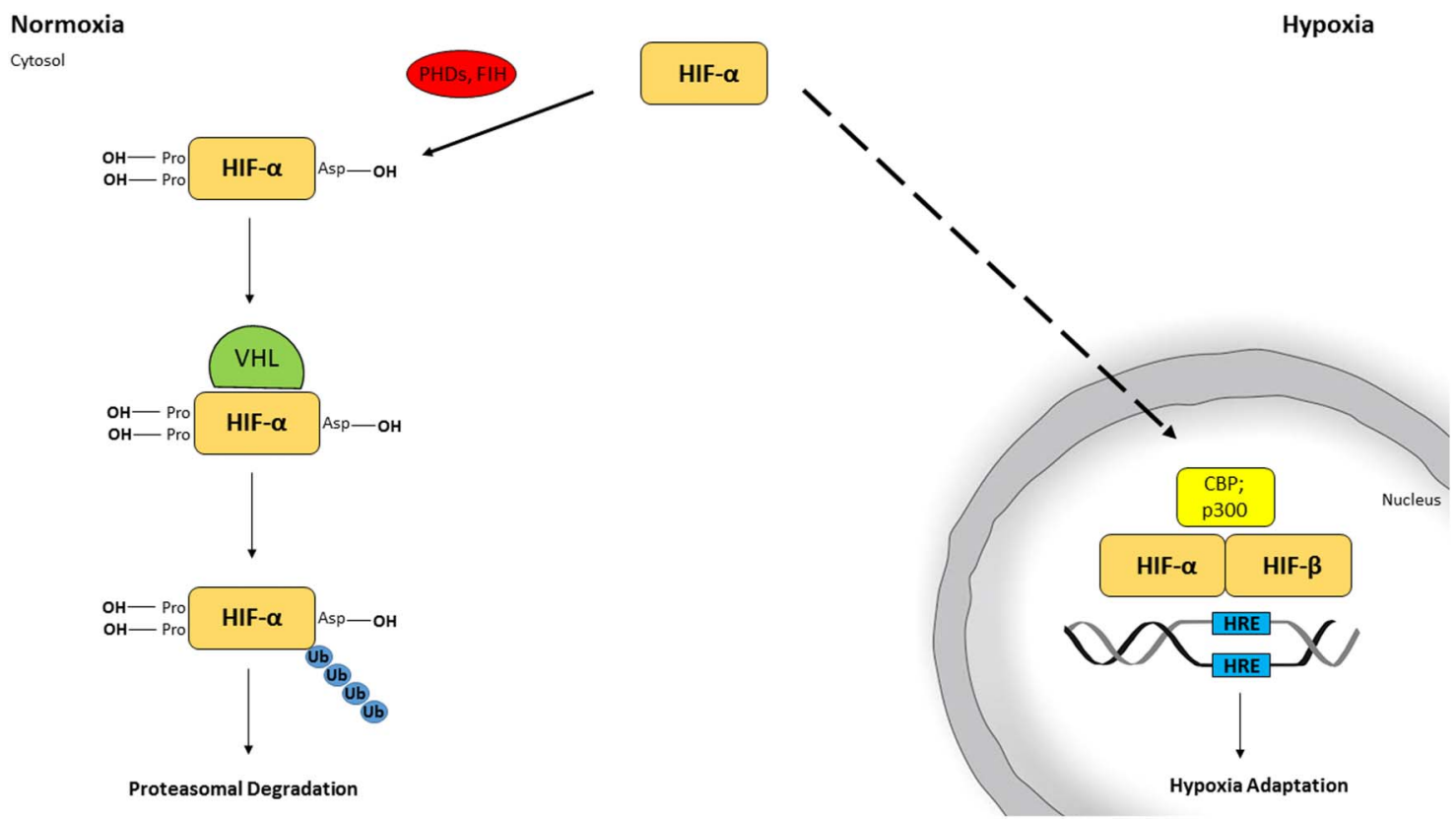

Figure 2 HIF-pathway in normoxia and hypoxia. In the presence of molecular oxygen, PHDs hydroxylate HIF- $\alpha$ promotes its interaction with the von Hippel-Lindau E3 ligase complex. This complex mediates ubiquitination and the proteasomal degradation of HIF- $\alpha$. Factor inhibiting HIF-dependent ASN hydroxylation prevents interactions between HIF- $\alpha$ subunitsand CBP/p300 and thus prevents transactivation. In hypoxia, the HIF hydroxylases are inactivated and therefore HIF- $\alpha$ can heterodimerize with HIF-1 $\beta$, translocate to the nucleus, and interact with transcriptional coactivators (eg, $\mathrm{CPB} / \mathrm{p} 300)$ to mediate the transcription of genes involved in adaptation.

Other studies have indicated that LPS-dependent signaling can increase HIF-1 accumulation by decreasing its rate of degradation. In normoxia, LPS-induced TLR stimulation decreases the mRNA encoding PHD2 and PHD3 genes in myeloid cells. ${ }^{80}$ Moreover, LPS induces the production of ROS via activation of nicotinamide adenine dinucleotide phosphate oxidase, and this leads to a change in the intracellular redox status of macro-phages. ${ }^{89}$ Reactive oxygen species oxidize the $\mathrm{Fe}(\mathrm{II})$ at the catalytic site of the PHDs hydroxylases, thus blocking their activity, which requires iron for their catalytic activity. ${ }^{90}$ These results further underscore the complex relationship between TLR- and hypoxia-dependent signaling pathways.

Recently, it has been suggested that shingosine kinase 1 also mediates LPS-induced, ROS-dependent activation of HIF- $1 \alpha$ through extracellular signal-regulating kinase, PLC $-1 \gamma$ and PI3 kinase pathways. Shingosine kinase 1 then participates to the assembly/activation of the nicotinamide adenine dinucleotide phosphate oxidase complex that produces ROS and activates both HIF- $1 \alpha$, which contributes to the production of the proinflammatory cytokines. ${ }^{91}$

In addition, in activated macrophages, LPS induces accumulation of succinate, which stabilizes HIF- $1 \alpha$. Succinate directly stabilizes HIF- $1 \alpha$ by inhibition of the PHD activity or indirectly by inducing ROS. ${ }^{92}$ In human monocytederived DCs, LTA (lipoteichoic acid)-induced TLR2 and LPS-induced TLR4 trigger stabilization of HIF-1 $\alpha$, which in turn induces maturation of monocyte-derived DCs and secretion of VEGF and proinflammatory cytokines. ${ }^{81}$

A screen of all mammalian TLRs revealed a consistent induction of TLR2 and TLR6 in hypoxia in bone marrowderived DCs, endothelial cells (HMEC-1), epithelial cells (Caco-2), and monocytes (MM6). Hypoxia inducible factor
1 was involved in the coordination of this response because hypoxia response elements were identified in both $t \operatorname{lr} 2$ and tir6 genes. $^{82}$ The up-regulation of TLRs in hypoxia enhances the recognition of PAMPs during inflammation.

Studies of a model of LPS-induced sepsis demonstrate that HIF- $1 \alpha$ promotes the disease through the production of cytokines such as TNF- $\alpha$, IL-1, and IL-12. As consequence, hif- $1 \alpha$ deletion in myeloid cells resulted in protection against LPS- induced sepsis in mice. ${ }^{80}$ However, pharmacologic activation of HIF using the hydroxylase inhibitor dimethyloxaloglycine (DMOG) had an antiinflammatory effect in a number of studies. For example, Hams et al. ${ }^{93}$ demonstrated that pretreatment with DMOG was beneficial in mice models of LPS-induced sepsis. After DMOG treatment, mice demonstrated resistance to challenge with LPS, although these mice were more susceptible to bacterial sepsis. ${ }^{93}$ This refractory state seems to occur through an increase of IL-10, an anti-inflammatory cytokine that protected the body from an immune overreaction that could turn into tissue damage and pathologic state. This work supports a protective antiinflammatory role of HIF-hydroxylase inhibition in acute systemic inflammation induced by LPS. ${ }^{93}$ In a separate study, it was demonstrated that HIF-hydroxylase inhibition reduced IL-1 $\beta$-dependent signaling in in vitro and in vivo indicating an additional mechanism of anti-inflammatory action. ${ }^{94}$

In summary, the TLR and hypoxia-dependent pathways are ancient mechanisms, which have evolved to provide an organism to respond to the challenges of infection and hypoxia, respectively. Although we have now got a clear understanding of the mechanisms underpinning each of these pathways, the vital importance of crosstalk between them in a variety of physiologic and pathophysiologic 
conditions is starting to become appreciated. Because of the fundamental importance of these pathways, it is likely that the development of new therapeutics targeting their activity will be new and exciting possibilities for the treatment of infection and inflammatory disease states.

Provenance and peer review Commissioned; internally peer reviewed.

\section{REFERENCES}

1 Murphy K. Janeway's Immunobiology 8th ed. Garland Science; 2011.

2 Akira S, Uematsu S, Takeuchi O. Pathogen recognition and innate immunity. Cell 2006:124:783-801.

3 Beutler BA. TLRs and innate immunity. Blood 2009;113:1399-407.

4 Anderson KV, Bokla L, Nüsslein-Volhard C. Establishment of dorsal-ventral polarity in the Drosophila embryo: the induction of polarity by the Toll gene product. Cell 1985:42:791-8.

5 Lemaitre B, Nicolas E, Michaut L, et al. The dorsoventral regulatory gene cassette spatzle/Toll/cactus controls the potent antifungal response in Drosophila adults. Cell 1996;86:973-83.

6 Medzhitov R, Preston-Hurlburt P Janeway CAJr. A human homologue of the Drosophila Toll protein signals activation of adaptive immunity. Nature 1997;388:394-7.

7 Pandey S, Kawai T, Akira S. Microbial sensing by toll-like receptors and intracellular nucleic acid sensors. Cold Spring Harb Perspect Med 2015;5: a016246.

8 Poltorak A, He X, Smirnova I, et al. Defective LPS signaling in $\mathrm{C} 3 \mathrm{H} / \mathrm{HeJ}$ and C57BL/10ScCr mice: mutations in Tlr4 gene. Science 1998;282:2085-8.

9 Takeuchi O, Hoshino K, Kawai T, et al. Differential roles of TLR2 and TLR4 in recognition of gram-negative and gram-positive bacterial cell wall components. Immunity 1999;11:443-51.

10 Schwandner R, Dziarski R, Wesche $H$, et al. Peptidoglycan- and lipoteichoic acid-induced cell activation is mediated by toll-like receptor 2. J Biol Chem 1999:274:17406-9.

11 Means TK, Lien E, Yoshimura A, et al. The CD14 ligands lipoarabinomannan and lipopolysaccharide differ in their requirement for Toll-like receptors. J Immunol 1999;163:6748-55.

12 Campos MA, Almeida IC, Takeuchi O, et al. Activation of Toll-like receptor-2 by glycosylphosphatidylinositol anchors from a protozoan parasite. J Immunol 2001;167:416-23.

13 Underhill DM, Ozinsky A, Hajjar AM, et al. The Toll-like receptor 2 is recruited to macrophage phagosomes and discriminates between pathogens. Nature 1999;401:811-5.

14 Bieback K, Lien E, Klagge IM, et al. Hemagglutinin protein of wild-type measles virus activates toll-like receptor 2 signaling. I Virol 2002:76:8729-36

15 Ozinsky A, Underhill DM, Fontenot JD, et al. The repertoire for pattern recognition of pathogens by the innate immune system is defined by cooperation between toll-like receptors. Proc Natl Acad Sci USA 2000:97:13766-71.

16 Takeuchi O, Kawai T, Mühlradt PF, et al. Discrimination of bacterial lipoproteins by Toll-like receptor 6. Int Immunol 2001;13:933-40.

17 Hayashi F, Smith KD, Ozinsky A, et al. The innate immune response to bacterial flagellin is mediated by Toll-like receptor 5 . Nature 2001:410:1099-103.

$18 \mathrm{Kim} \mathrm{D}$, Kim YJ, Koh HS, et al. Reactive oxygen species enhance TLR10 expression in the human monocytic cell line THP-1. Int J Mol Sci 2010;11:3769-82.

19 Lee SM, Kok KH, Jaume M, et al. Toll-like receptor 10 is involved in induction of innate immune responses to influenza virus infection. Proc Natl Acad Sci USA 2014;111:3793-8.

20 Guan Y, Ranoa DR, Jiang S, et al. Human TLRs 10 and 1 share common mechanisms of innate immune sensing but not signaling. J Immunol 2010;184:5094-103.

21 Blasius AL, Beutler B. Intracellular toll-like receptor. Immunity 2010:32:305-15.

22 Latz E, Verma A, Visintin A, et al. Ligand-induced conformational changes allosterically activate Toll-like receptor 9. Nat Immunol 2007;8:772-9.

23 Tanji H, Ohto U, Shibata T, et al. Structural reorganization of the Toll-like receptor 8 dimer induced by agonistic ligands. Science 2013;339:1426-9.

24 Muzio M, Bosisio D, Polentarutti N, et al. Differential expression and regulation of toll-like receptors (TLR) in human leukocytes: selective expression of TLR3 in dendritic cells. J Immunol 2000;164:5998-6004.
25 Alexopoulou L, Holt AC, Medzhitov R, et al. Recognition of double stranded RNA and activation of NF-kB by Toll-like receptor 3. Nature 2001:413:732-8.

26 Wang JP, Asher DR, Chan M, et al. Cutting Edge: Antibody-mediated TLR7-dependent recognition of viral RNA. J Immunol 2007:178:3363-7.

27 Biondo C, Malara A, Costa A, et al. Recognition of fungal RNA by TLR7 has a nonredundant role in host defense against experimental candidiasis. Eur J Immunol 2012;42:2632-43.

28 Mancuso G, Gambuzza M, Midiri A, et al. Bacterial recognition by TLR7 in the lysosomes of conventional dendritic cells. Nat Immunol 2009;10:587-94.

29 Hornung V, Guenthner-Biller M, Bourquin C, et al. Sequence-specific potent induction of IFN-alpha by short interfering RNA in plasmacytoid dendritic cells through TLR7. Nat Med 2005;11:263-70.

30 Hemmi H, Takeuchi O, Kawai T, et al. A Toll-like receptor recognizes bacterial DNA. Nature 2000;408:740-5.

31 Krug A, French AR, Barchet W, et al. TLR9-dependent recognition of MCMV by IPC and DC generates coordinated cytokine responses that activate antiviral NK cell function. Immunity 2004;21:107-19.

32 Bafica A, Santiago HC, Goldszmid R, et al. Cutting edge: TLR9 and TLR2 signaling together account for MyD88-dependent control of parasitemia in trypanosoma cruzi infection. J Immunol 2006;177:3515-9.

33 Takahashi K, Shibata T, Akashi-Takamura S, et al. A protein associated with Toll-like receptor (TLR) 4 (PRAT4A) is required for TLR-dependent immune responses. J Exp Med 2007;204:2963-76.

34 Brinkmann MM, Spooner E, Hoebe K, et al. The interaction between the ER membrane protein UNC93B and TLR3, 7, and 9 is crucial for TLR signaling. J Cell Biol 2007;177:265-75.

35 Tabeta K, Hoebe K, Janssen EM, et al. The Unc93b1 mutation 3d disrupts exogenous antigen presentation and signaling via Toll-like receptors 3, 7 and 9. Nat Immunol 2006; 7:156-64.

36 Kobe B, Deisenhofer J. Proteins with leucine-rich repeats. Curr Opin Struct Biol 1995:5:409-16.

37 Rock FL, Hardiman G, Timans JC, et al. A family of human receptors structurally related to Drosophila Toll. Proc Natl Acad Sci USA 1998;95:588-93.

38 Dunne A, O'Neill LA. The interleukin-1 receptor/Toll-like receptor superfamily: signal transduction during inflammation and host defense. SCi STKE 2003;2003:re3.

39 Wright SD, Ramos RA, Tobias PS, et al. CD14, a receptor for complexes of lipopolysaccharide (LPS) and LPS binding protein. Science 1990;249:1431-3.

40 Shimazu R, Akashi S, Ogata H, et al. MD-2, a molecule that confers lipopolysaccharide responsiveness on Toll-like receptor 4. J Exp Med 1999;189:1777-82.

41 O'Neill LA, Bowie AG. The family of five: TIR-domain-containing adaptors in Toll-like receptor signalling. Nat Rev Immunol 2007;7:353-64.

42 Medzhitov R, Preston-Hurlburt P, Kopp E, et al. MyD88 is an adaptor protein in the hToll/lL-1 receptor family signaling pathways. Mol Cell 1998;2:253-8.

43 Kawai T, Adachi O, Ogawa T, et al. Unresponsiveness of MyD88-deficient mice to endotoxin. Immunity 1999;11:115-22.

44 Honda K, Yanai H, Mizutani T, et al. Role of a transductional-transcriptional processor complex involving MyD88 and IRF-7 in Toll-like receptor signaling. Proc Natl Acad Sci USA 2004;101:15416-21.

45 Takaoka A, Yanai H, Kondo S, et al. Integral role of IRF-5 in the gene induction programme activated by Toll-like receptors. Nature 2005;434:243-9.

46 Negishi H, Fujita Y, Yanai H, et al. Evidence for licensing of IFN-gamma-induced IFN regulatory factor 1 transcription factor by MyD88 in Toll-like receptor-dependent gene induction program. Proc Natl Acad Sci USA 2006:103:15136-41.

47 Kawai T, Akira S. Toll-like receptors and their crosstalk with other innate receptors in infection and immunity. Immunity 2011;34:637-50.

48 Peng J, Yuan Q, Lin B, et al. SARM inhibits both TRIF- and MyD88-mediated AP-1 activation. Eur J Immunol 2010;40:1738-47.

49 Gilmore TD. The Rel/NF-kappaB signal transduction pathway: introduction. Oncogene 1999;18:6842-4.

50 Wesche $\mathrm{H}$, Henzel WJ, Shillinglaw W, et al. MyD88: an adapter that recruits IRAK to the IL-1 receptor complex. Immunity 1997;7:837-47.

51 Lin SC, Lo YC, Wu H. Helical assembly in the MyD88-IRAK4-IRAK2 complex in TLR/L-1R signalling. Nature 2010;465:885-90.

52 Clark K, Nanda S, Cohen P. Molecular control of the NEMO family of ubiquitin-binding proteins. Nat Rev Mol Cell Biol 2013;14:673-85.

53 Napetschnig J, Wu H. Molecular basis of NF-kappaB signaling. Annu Rev Biophys 2013;42:443-68

54 Taylor CT, McElwain JC. Ancient atmospheres and the evolution of oxygen sensing via the hypoxia-inducible factor in metazoans. Physiology (Bethesda) 2010;25:272-9. 
55 Alberts B, Bray D, Hopkin K, et al. Molecular Biology of the Cells 4th ed. New York: Garland Science; 2014.

56 Rich PR. The molecular machinery of Keilin's respiratory chain. Biochem Soc Trans 2003;31:1095-105.

57 Rolfe DF, Brown GC. Cellular energy utilization and molecular origin of standard metabolic rate in mammals. Physiol Rev 1997;77:731-58.

58 Semenza GL, Wang GL. A nuclear factor induced by hypoxia via de novo protein synthesis binds to the human erythropoietin gene enhancer at a site required for transcriptional activation. Mol Cell Biol 1992;12:5447-54.

59 Semenza GL. Targeting HIF-1 for cancer therapy. Nat Rev Cancer 2003;3:721-32.

60 Hanahan D, Weinberg RA. Hallmarks of cancer: the next generation. Cell 2011;144:646-74.

61 lyer NV, Kotch LE, Agani F, et al. Cellular and developmental control of $\mathrm{O}_{2}$ homeostasis by hypoxia-inducible factor 1 alpha. Genes Dev 1998;12:149-62.

62 Semenza GL, Jiang BH, Leung SW, et al. Hypoxia response elements in the aldolase $\mathrm{A}$, enolase 1 , and lactate dehydrogenase $\mathrm{A}$ gene promoters contain essential binding sites for hypoxia-inducible factor 1. J Biol Chem 1996;271:32529-37.

63 Kim JW, Tchernyshyov I, Semenza GL, et al. HIF-1-mediated expression of pyruvate dehydrogenase kinase: a metabolic switch required for cellular adaptation to hypoxia. Cell Metab 2006;3:177-85.

64 Fukuda R, Zhang H, Kim JW, et al. HIF-1 regulates cytochrome oxidase subunits to optimize efficiency of respiration in hypoxic cells. Cell 2007;129:111-22.

65 Wang GL, Semenza GL. Purification and characterization of hypoxia-inducible factor 1. J Biol Chem 1995;270:1230-7.

66 Ema M, Taya S, Yokotani N, et al. A novel bHLH-PAS factor with close sequence similarity to hypoxia-inducible factor 1alpha regulates the VEGF expression and is potentially involved in lung and vascular development. Proc Natl Acad Sci USA 1997;94:4273-8.

67 Flamme I, Fröhlich T, von Reutern M, et al. HRF, a putative basic helix-loop-helix-PAS-domain transcription factor is closely related to hypoxia-inducible factor-1 alpha and developmentally expressed in blood vessels. Mech Dev 1997;63:51-60.

68 Schofield CJ, Ratcliffe PJ. Oxygen sensing by HIF hydroxylases. Nat Rev Mol Cell Biol 2004;5:343-54.

69 Epstein AC, Gleadle JM, McNeill LA, et al. C. elegans EGL-9 and mammalian homologs define a family of dioxygenases that regulate HIF by prolyl hydroxylation. Cell 2001;107:43-54

70 Kaelin WGJr Ratcliffe PJ. Oxygen sensing by metazoans: the central role of the HIF hydroxylase pathway. Mol Cell 2008;30:393-402.

71 Mahon PC, Hirota K, Semenza GL. FIH-1: a novel protein that interacts with HIF-1alpha and VHL to mediate repression of HIF-1 transcriptional activity. Genes Dev 2001;15:2675-86.

72 Bruick RK, McKnight SL. A conserved family of prolyl-4-hydroxylases that modifies HIF. Science 2001;294:1337-40.

73 Jaakkola P, Mole DR, Tian YM, et al. Targeting of HIF-alpha to the von Hippel-Lindau ubiquitylation complex by $\mathrm{O}_{2}$-regulated prolyl hydroxylation. Science 2001:292:468-72.

74 Lando D, Peet DJ, Gorman JJ, et al. FIH-1 is an asparaginyl hydroxylase enzyme that regulates the transcriptional activity of hypoxia-inducible factor. Genes Dev 2002;16:1466-71.

75 Hagen T, Taylor CT, Lam F, et al. Redistribution of intracellular oxygen in hypoxia by nitric oxide: effect on HIF1alpha. Science 2003;302:1975-8.
76 Taylor CT. Mitochondria and cellular oxygen sensing in the HIF pathway. Biochem J 2008;409:19-26.

77 Nizet $\mathrm{V}$, Johnson RS. Interdependence of hypoxic and innate immune responses. Nat Rev Immunol 2009;9:609-17.

78 Colgan SP, Taylor CT. Hypoxia: an alarm signal during intestinal inflammation. Nat Rev Gastroenterol Hepatol 2010;7:281-7.

79 Cramer T, Yamanishi Y, Clausen BE, et al. HIF-1alpha is essential for myeloid cell-mediated inflammation. Cell 2003;112:645-57.

80 Peyssonnaux C, Cejudo-Martin P Doedens A, et al. Cutting edge: Essential role of hypoxia inducible factor-1alpha in development of lipopolysaccharide-induced sepsis. J Immunol 2007:178:7156-9.

81 Spirig R, Djafarzadeh S, Regueira T, et al. Effects of TLR agonists on the hypoxia-regulated transcription factor HIF-1alpha and dendritic cell maturation under normoxic conditions. PLoS One 2010;5(6):e0010983.

82 Kuhlicke J, Frick JS, Morote-Garcia JC, et al. Hypoxia inducible factor (HIF)-1 coordinates induction of Toll-like receptors TLR2 and TLR6 during hypoxia. PLoSOne 2007;2(12):e1364.

83 Frede S, Stockmann C, Freitag P, et al. Bacterial lipopolysaccharide induces HIF-1 activation in human monocytes via p44/42 MAPK and NF-kappaB. Biochem J 2006;396:517-27.

84 Mi Z, Rapisarda A, Taylor L, et al. Synergystic induction of HIF-1alpha transcriptional activity by hypoxia and lipopolysaccharide in macrophages. Cell Cycle 2008;7:232-41.

85 Ramanathan M, Pinhal-Enfield G, Hao I, et al. Synergistic up-regulation of vascular endothelial growth factor (VEGF) expression in macrophages by adenosine A2A receptor agonists and endotoxin involves transcriptional regulation via the hypoxia response element in the VEGF promoter. Mol Biol Cell 2007:18:14-23.

86 Sumbayev VV. LPS-induced Toll-like receptor 4 signalling triggers cross-talk of apoptosis signal-regulating kinase 1 (ASK1) and HIF-1alpha protein. FEBS Lett 2008;582:319-26.

87 Cummins EP, Berra E, Comerford KM, et al. Prolyl hydroxylase-1 negatively regulates IkappaB kinase-beta, giving insight into hypoxia-induced NFkappaB activity. Proc Natl Acad Sci USA 2006;103:18154-9.

88 Rius J, Guma M, Schachtrup C, et al. NF-kappaB links innate immunity to the hypoxic response through transcriptional regulation of HIF-1alpha. Nature 2008:453:807-11.

89 Nishi K, Oda T, Takabuchi S, et al. LPS induces hypoxia-inducible factor 1 activation in macrophage-differentiated cells in a reactive oxygen species-dependent manner. Antioxid Redox Signal 2008;10:983-95.

90 Gerald D, Berra E, Frapart YM, et al. JunD reduces tumor angiogenesis by protecting cells from oxidative stress. Cell 2004:118:781-94.

91 Pchejetski D, Nunes J, Coughlan K, et al. The involvement of sphingosine kinase 1 in LPS-induced Toll-like receptor 4-mediated accumulation of HIF- $\alpha$ protein, activation of ASK1 and production of the pro-inflammatory cytokine IL-6. Immunol Cell Biol 2011:89:268-74.

92 Tannahill GM, Curtis AM, Adamik J, et al. Succinate is an inflammatory signal that induces IL-1 $\beta$ through HIF-1 $\alpha$. Nature 2013:496:238-42.

93 Hams E, Saunders SP, Cummins EP, et al. The hydroxylase inhibitor dimethyloxallyl glycine attenuates endotoxic shock via alternative activation of macrophages and IL-10 production by B1 cells. Shock 2011:36:295-302.

94 Scholz CC, Cavadas MA, Tambuwala MM, et al. Regulation of IL-1 $1 \beta$-induced $\mathrm{NF}-\kappa \mathrm{B}$ by hydroxylases links key hypoxic and inflammatory signaling pathways. Proc Natl Acad Sci USA 2013;110:18490-5. 